\title{
Standards for Effective Insect Rearing Science and Technology Papers
}

\author{
Allen Carson Cohen \\ Insect Rearing Education \& Research Program, Department of Entomology and Plant Pathology, North Carolina State University, \\ Raleigh, NC, USA \\ Email: a ccohen@ncsu.edu
}

How to cite this paper: Cohen, A.C. (2018) Standards for Effective Insect Rearing Science and Technology Papers. Advances in Entomology, 6, 256-284. https://doi.org/10.4236/ae.2018.64020

Received: July 30, 2018

Accepted: October 21, 2018

Published: October 24, 2018

Copyright (c) 2018 by author and Scientific Research Publishing Inc. This work is licensed under the Creative Commons Attribution International License (CC BY 4.0).

http://creativecommons.org/licenses/by/4.0/

\section{(c) (†) Open Access}

\begin{abstract}
This article suggests standards for insect rearing papers, to make them more suitable for publication. It provides guidelines for publishing 1) insect rearing-technology papers and 2) insect rearing-science papers. The technology papers offer rearing methodology or practical aspects of rearing system development and optimization. The rearing science papers would include outcomes of rearing experiments developed with controls, variables and are based on explicitly stated rationale and explicit hypotheses. This paper also suggests welcoming papers based on discoveries of various aspects of feeding biology and treating scientifically rearing systems' components and properties. It is suggested that the treatment of insect rearing systems should be modelled after the extensive and successful practices of the food science and food technology community. The food science model includes welcoming papers that do not involve directly living subjects. It is argued here that the outcomes of following these suggestions will greatly enhance the progress of insect rearing inquiry, and this progress will support a much greater practical and basic science-based understanding of insect biology.
\end{abstract}

\section{Keywords}

Rearing Research

\section{Overview and History}

Insect rearing systems as described by Cohen are intricately interwoven networks or webs of materials that have complex interactions between components and within the framework of the target insects' biology [1] [2] [3] and [4]. Table 1 provides an indication of the importance of insects whose source is a rearing system. In fact, rearing systems have been described as human-designed 
Table 1. Source of insects used in studies in 10 randomly selected issues of the Annals of the Entomological Society of America (Annals), the Journal of Economic Entomology (JEE), Environmental Entomology (Environ.), and the Archives of Insect Biochemistry and Physiology (Archives) published in 1998-1999.

\begin{tabular}{cccccc}
\hline Source of Insects & \multicolumn{5}{c}{ Journal } \\
\hline Field & Annals & JEE & Environ. & Archives & Totals \\
\hline Reared on "natural" diet $b$ & 77 & 104 & 41 & 5 & 227 \\
Reared on artificial diet $c$ & 48 & 79 & 54 & 16 & 187 \\
Total & 157 & 287 & 126 & 50 & 620 \\
\hline
\end{tabular}

Table 1 shows the relative importance of insects in 600 studies published in Entomological Society of America journals published in 1998 and 1999 (cited by Cohen [4]).

ecosystems or microcosms of an insect's world [1]. This means diet, all environmental requirements (temperature, water, light, air, soil, and all other environmental factors), reproductive accommodations (mating space, oviposition sites), and social structure accommodations must be provided. Also, the rearing system context must include containment, and access for personnel to conduct their care in providing food, cleaning, harvesting, and any other special functions that must be engineered into the rearing process. In an early milestone paper Delcourt and Guyenot 1910 [5] presented the foundation of insect rearing systems: control. Throughout the development of rearing systems over the past century, the concept of control has been the driving force behind nearly all published rearing advancements. The rearing system concept entails an engineering basis, and all aspects of rearing systems lend themselves to control strategies that are in accord with the principles of systems engineering.

Over the 108 years since the Delcourt and Guyenot paper [5] on control of insect rearing, thousands of publications contain various aspects of rearing systems detailing the tactics of providing microenvironments that provided temperature, moisture (humidity), light conditions, gas exchange, reproductive needs, protection from contaminating microbes, and various other requirements that are met in nature but must be deliberately provided for captive insects. Despite the large number of papers that treat some aspects of insect rearing, it is apparent to long-time practitioners of insect rearing, that the publications represent only a "tip of the iceberg" of all that is practiced in rearing facilities. There are several reasons for the gaps in the body of published rearing information: 1) In some rearing operations, innovations are proprietary. 2) Some organizations that develop and use rearing procedures are structured to solve problems but do not have a publication "culture." 3) Inmany cases, rearing innovations are considered tangential or incidental to the main purpose of a project, so the rearing part of a program gets neglected. 4) The infrastructure of journals and other publication outlets does not contain a formal structure for communicating rearing information. For Item 1), it is clear that for organizations that 
profit from efficient rearing of an insect, divulging their techniques would possibly threaten their advantage over competitors. This could include operations where the rearing is to produce insects as a product or where the insects are used for research for product testing. For Item 2), organizations such as the USDA, APHIS or USDA, Forest Service are charged with solving problems such as control of invasive pests, and their mission does not include transfer of technology or scientific understanding.

For Item 3), development or adoption of a rearing system is generally considered an incidental part of the main program such as biological control, sterile insect techniques, or some other pest control process. Similarly, scientists who use insects as research subjects often regard the rearing process as a necessary but trivial inconvenience as an avenue to doing research with such disciplines as host plant resistance, genetic pest management, insect physiology/biochemistry, and numerous other research purposes. In my experience, many researchers pay more attention to the characteristics and of an electrophoresis gel or liquid chromatography column than they do to the insects upon which their research outcomes depend! The thinking of these researchers seems to be, "if my Lygus lineolaris or my Heliothis virescens is alive, then it is suitable for the experiments I am performing."

Item 4) is one of the most serious barriers to improved communication of rearing advancements: it is the lack of a clearly-defined set of standards for rearing publications. Lacking such standards, researchers must design their studies according to their interpretation of papers they choose to use as models or they must invent novel designs, and in turn, editors and reviewers must judge the merits of the papers without clear guidelines or standards [1] [2] [3] and [4]. Authors, editors, reviewers, and readers are therefore left with questions as to whether a rearing contribution must be completely successful, novel, and of sweeping scope to be worthy of publication. By "completely successful," I am saying that many reviewers consider a paper unworthy of publication unless it presents a complete, de novo system of mass-rearing a species that has not been reared previously. This is in contrast with "incremental accomplishments," which offer improvements in existing systems or steps towards a completely developed mass-rearing system. The advancements in completely successful systems can be considered salutatory progress vs. incremental progress. Although there could be a problem with overloading the literature with trivial progress reports, there is another problem with overly stringent expectations that filter out accomplishments that may appear to be minor but actually have far-reaching potential [1] [2] [3] and [4].

\section{The Concept of Control}

The centerpiece of rearing systems and the first topic addressed here is an appropriate diet. Diets must meet requirements of palatability, nutritional value, bioavailability, and stability [1]. They are profoundly influenced by nuances of 
types of materials used in them and the processes used to make them. They are technological constructs that may have been developed sometimes by heuristic procedures or sometimes by detailed engineering approaches [1]. Since Bogdanow $(1906,1908)[6]$ and [7] reported an artificial diet for blowflies, thousands of insect diet papers have been published, and trillions of insects have been reared on artificial media. Diet-based mass-rearing programs include sterile insect techniques for tephritidflies, screwworms, and pink bollworms, as well as tens of billions of feeder insects and insects for biological control. Also of vast importance is the extensive research made possible by diet-based rearing techniques cannot be overstated. Considering the successes of diets as centerpieces of rearing systems and the dependence of science and society on the capability to produce healthy insects on diets, it would seem self-evident that diet research would have a strong standing in the scientific community. However, despite the many successes in diet-based rearing systems, there remain many barriers to the research and reporting of diet accomplishments. Although several of the earliest papers-dealing with Drosophila diets-were published in our most respected journals (Science, Nature, the Proceedings of the National Academy of Science, 1910-1925), a cryptic trend emerged where insect diet papers and other rearing reports were not welcomed by journals. Over four decades, I have tried to understand why this trend developed and what could be done to correct it.

Based on my studies of rearing/diet papers and acquaintanceship with rearing/diet specialists, I conclude a major problem is that we lack clear standards upon which researchers can model their studies and that reviewers and editors can use to evaluate the reports. The problems are in four areas: 1) many diet papers lack a sound scientific or technological basis. 2) Many useful findings "fall through the cracks" and are never published or they appear only as cryptic information that is extraneous to diet and rearing advancements. 3) The audience or stakeholders of diet research accomplishments regard the findings simplistically and without respect for the difficulties of diet research and the potentially rich intellectual understanding which diet/feeding biology studies can provide. 4) The audience of diet research is chronically concerned that incremental accomplishments or negative data will be published and will somehow dilute the quality of entomology journals. The outcome of these concerns is that a great deal of information fails to be published, sometimes because of the threat of rejection, what I consider a "flinching" on the part of researchers who know in advance that if they try to publish a study that does not have sweeping success to report, the effort to publish will be treated with condescension and rejection [2].

\section{Changing Our Paradigms about Insect Rearing}

The scientific community would profit from adopting some changes in how rearing publications should be conceived by rearing researchers and their audience, including editors and reviewers of rearing papers. Therefore, I suggest here that insect rearing systems should be regarded as: 1) tools of inquiry about 
insect biology, 2) tools for study of rearing system components and their interactions.

1) Tools of inquiry about insect biology. This point is based on the reciprocal interactions between basic science of insects' biology and applied, technological accomplishments with rearing systems. For example, knowledge of feeding biology such as properties of peritrophic matrices or enzyme characteristics in extra-oral digestion inform diet development researchers about how incipient diets are being utilized by insect targets. A compelling example of the connection between the basic and applied science (technology) is to be found in the teachings of Vincent G. Dethier on the reflex of fly proboscis in response to stimulation be certain chemical stimuli, leading to technological outcomes such as development of diets for a wide variety of insects and a tremendous advancement of our understanding of complex sensory stimuli and feeding responses [8]. The works of Hamamura [9] [10] (1959 and 2001) on silkworm diets are a wonderful testimony to the basic science/diet technology outcomes as are numerous works by Fraenkel, Beck, Schoonhoven, Chippendale, Vanderzant and others who worked seamlessly and productively on basic and practical aspects of what I call "feeding biology" or "feeding science" [3] (Cohen 2015).

2) Tools for study of component and process interactions and effects (i.e. study of the physical/chemical properties of diets as well as their biological properties. This potentiates studies of insect diets in parallel approaches to the highly productive studies of human foods and feeds for livestock and pets. This opens a place for formal studies of the science and technology of rearing systems. Rearing system science is the approach to understanding mechanisms, cause and effect relationships, and the discovery of the nature of rearing system components. Rearing system technology is the practical application of the scientific principles; it is the application and invention that stems from problem-solving inquiry. Although the relationships of or distinctions between science and technology can be philosophical and abstract, a working framework ascribes to science inquiry, causal relationships, predictions, and understanding of the principles of nature. Technology encompasses invention and practical ability to construct useful products-in this case, insect rearing systems. Although commonly the terms "science" and "technology" are used as indistinguishable pairs, there are important commonalities and distinctions for our purposes in dealing with insect rearing systems. In the process of inquiry about rearing system science and technology, the rationale behind a specific inquiry is important in both domains. Because science is concerned with discovery of cause and effect relationships, science-based rearing system inquiry should be hypothesis driven. However, for rearing technology advancements (inventions), we are more concerned with what works for our practical purposes. Often, but not always, understanding of the scientific basis of a technological breakthrough helps researchers and inventors reach practical, heuristic outcomes; the science behind an outcome may not be testable and may not be required to use rigorous, repeatable techniques in developing a useful rearing system (or sub-system). 


\section{Standards for Rearing Papers}

1) Rearing Science and Rearing Technology Papers: Rearing papers of two kinds should be welcomed: a) rearing-technology and b) rearing-science. Rearing technology papers would include descriptions of rearing-related processes, including innovations in diet synthesis procedures (size-reduction, mixing, heating, post-synthesis conditions, etc.), diet presentation procedures (forming diet configurations, packaging, preservation, etc.). The types of advancements made in deriving mass-rearing systems from laboratory scale systems should be welcomed here. An excellent example of this is the development of the twin-screw extruder system used for mass-rearing pink bollworms. This important innovation was published in an engineering journal (Edwards et al. 1996 [11]), rather than an entomological outlet. This point is further developed below in the specific recommendations for the technology and science papers.

2) Explicit Rationale and Hypotheses: Both rearing-technology and rearing-science papers should be based on a clearly stated rationale, and science papers should be further based on clearly stated hypotheses. Four examples of clear statement of rationale are found in early papers on Drosophila rearing. Baumberger [12] explained that because yeasts were found to be the principle natural food of Drosophila spp., he included them in his artificial diet for these flies. He also explained a rationale for using agar in diets because of the convenience of counting fly eggs in a semi-clear medium [13]. Similarly, Guyenot [14] explained the basis of using controlled conditions for rearing Drosophila spp., and he also explained his rationale for using live yeast as a rearing component, based on his observations that the fly larvae appeared to consume substantial amounts of yeast, thanks to his observations of the low population density of yeast cells in cultures of Drosophila with high populations of fly larvae [15]. It is also exemplary that although Baumberger had made similar observations of the larva/yeast relationship, Baumberger [12] cited the earlier paper of Guyenot [15], which is a proper treatment of credit for discoveries by previous authors.

3) Physical/Chemical/Biological Properties of Rearing System Components: Papers should be welcomed without necessarily involving direct insect experimentation. A paper that deals with a diet's physical or chemical characteristics can be fully valuable without direct inclusion of insects. This characteristic is fully subscribed to in the human food community. Hundreds of food science and technology papers are published weekly that contain no direct involvement of human subjects. Food processing methods that protect known nutrients, improve texture (or other sensory and rheological qualities [3]), protect foods from microbial contamination, and other features are not subjected to tests with human (or other animal) subjects. The same should be applicable to insect diets, and the potential progress in dietetics would be immense. An important subset of this concept is that while we can gain a great deal from using food science and food technology literature, there are important aspects of insect diets that are unique to insect rearing. For example, insect diets are often unique mixtures of components that do not appear in human or livestock foods; furthermore, insect 
diets are often expected to last (remain stable) at rather high temperatures, high humidity, and for extended periods of time (often weeks). In addition to these issues, insect diets often serve as living places for target insects (with tunneling, use of diets and frass for refugia for pupation, or where frass and diets are closely associated). All these features lend themselves to the demand for (or clear benefit from) direct study of the characteristics and dynamics of insect diets, as well as other aspects of rearing systems.

4) Incremental vs. Saltatory Accomplishments Publishable: Often important rearing discoveries appear to be incremental rather than saltatory advancements. Many editors and critics of insect rearing papers have reasonable skepticism about the value of repeating previous works with only minor nuances of difference between the current work and what has already been thoroughly tested. However, it is often difficult and subjective to decide between trivial increments and important advancements. An excellent example of this issue is illustrated by the report of wheat germ in a diet for boll weevils (Vanderzant et al. 1959 [16]), which showed that except for a slight positive effect on oviposition, wheat germ did not seem to hold much promise as a diet ingredient. However, the next year when it was used in the diet of pink bollworms (Adkisson et al. 1960 [17]), wheat germ proved to be a highly useful diet component, which in fact, revolutionized diets for phytophagous insects.

5) Papers with Negative Results: Related to the points about incremental results are studies that offer negative results. Often negative results are not derived from flawed experimental designs, and the relentless denial of publication of papers with negative results has long been at odds with a major purpose of publication: the communication of important information that has been obtained through careful study. Automatic denial of papers that demonstrate only negative results not only hides important information from future researchers, but it also encourages authors to disguise or exaggerate results so that they can be viewed as positive. This point is discussed in detail by Cohen 2001 [4].

6) Utilization of Exploratory Statistics in Addition to Confirmatory Statistics: Statistically-based-strategies have long been used by engineers and food scientists to improve their systems, and recently diet researchers have utilized this approach productively (Assemi et al. 2012 [18], Lapointe et al. 2008 [19]). As I discussed in a summary on development and improvement of diets [3] (Cohen 2015) this approach has great potential for using statistical thinking to efficiently optimize diet development. Also, experimental packages such as Design of Experiments in SAS and JMP systems can be used for process control and quality control, and if these approaches are used early in the process of diet development they can become an excellent "package" of empirically-derived, well-vetted process control for diet production in mass-rearing systems.

7) Microbiomes and microbially-processed diets: Increasingly, procedures for determining the populations of microbes in insect microbiomes. These techniques lend themselves to highly productive studies of the roles of various microbes in domesticated vs. wild (or feral) insects' natural biota and the changes 
in this microbiome that result from artificial diet treatments. Furthermore, the literature on the involvement of various microbes in processing diet ingredients is ever-increasing and promising for greatly improved diet components [1] and [3]. Many robust techniques have become available in the last decade where molecular approaches make the identification and quantification of microbiota possible, often without the demands of culturing microbes that are fastidious and had previously defied identification [3].

8) Various aspects of palatability, nutritional value, bioavailability and stability of diets: these topics offer a rich potential for inquiry into what makes standard and "exotic" diet components useful and potentially enhancing to incipient diets. This certainly includes such topics as the character of diet matrices, structural properties of useful diets, and especially bioavailability. Once we have come to understand that failures in rearing are often attributable to problems with palatability, bioavailability and stability, we can gain useful perspective about the relative contributions that nutrition vs. these other three factors make in rearing successes and failures.

9) Unusual or novel subjects of insect diet papers including insects as human food: A small but growing body of information is emerging in refereed publications about production of insects intended for use as human food. Such papers could be useful if they are based on sound science and technology principles such as the study by Lund and Parrella 2015 [20]. Furthermore, other novel uses of insects may include such applications as using insects to detect explosives, insects as production systems (bioreactors) for novel pharmaceutical products such as human proteins ([3] Cohen 2015 reviews several such papers). Other uses for insects such as decorations and celebrations are in some sub-cultures a considerable enterprise.

\section{Rearing Technology vs. Rearing Science Papers: Specific Recommendations for Types of Papers that Would Be Valuable to the Scientific Community}

a) Rearing Technology Papers: Although several diet publications are of the type that I am calling "technology," too much very valuable technology (sometimes considered "methods") information is never published or is hidden so that the advancements are unavailable to our community. Over my 40 -years of study of diet development and rearing research, I have become aware of the loss of valuable information where researchers had ideas, often based on valuable experience, but were discouraged by editors and reviewers from expressing the rationale behind innovations or improvements in insect diet techniques.

An example of this is the development of the mass-rearing system for pink bollworms (Pectinophora gossypiella) used in the successful sterile insect technique (SIT) accomplished by the USDA, APHIS and cooperators from the growers' community and the State of California Department of Food and Agriculture. The basic diet that was the "grandparent" of the currently used medium, 
was the wheatgerm diet described by Adkisson et al. 1960 [17] (with roots in several earlier efforts to rear pink bollworms on artificial diet). In a chapter on pink bollworm rearing, Stewart 1984 [21] described the rearing technology that the USDA, APHIS facility in Phoenix, AZ USA had been using for a SIT program for 14 years prior to this chapter. In that chapter, Stewart [21] mentioned that the diet that facility used was essentially "from Ouye 1962 [22]." However, examination of the Ouye paper [22] reveals that several components were added to the 1984 diet [21]. Key components such as soy flour were not mentioned Ouye 1962 paper [22]. In fact, the use of soy components in insect diets mentioned in Western literature seems to have begun in the 1960s (e.g. by Redfern 1963 [23] and then by Shaver and Raulston 1971 [24]). The use of soy in Asian diets for mulberry silkworms (Bombyx mori) had been used for at least a couple of decades (summarized by Hamamura 2001 [10]) before it was adopted by Western researchers. It should be noted that there is a great deal of ambiguity about the terminology for soy components in insect diets (soy protein, soy protein isolate, soy flakes, soy flour, soy meal, defatted soy flour, full-fat soy flour, toasted soy flour, and raw soy flour. Even a seemingly unambiguous product such as Nutrisoy actually represents several different soy foods, including a brand of tofu and tempeh from Australia, a soy milk from Singapore, and a series of flours and meals from Archer, Daniels, Midland Company. The ambiguity of this terminology is a serious problem as the products mentioned here have vastly different qualities and will perform very differently if one is substituted for another. This soy issue reflects other diet components that can have vast differences nutritionally, in terms of palatability, bioavailability, and possibly in other ways in our insect diets. Such materials as yeast components, wheat germ, and even gelling agents can have significantly different behaviors in insect diets. The key point of all this is that diet papers should have very clear statements of the range of specifications for such potentially ambiguous components. The name of the company that is the source of the components can be helpful, but often this information retains an ambiguity. Therefore, a well-chosen set of technical specifications for potentially ambiguous or variable components should be part of the rearing paper.

A diet component such as soy flour can be listed as to source (company that supplied it), percent of protein, fats, fiber, sugar, ash, and if available mesh (range of particle size), and whether it is raw or heat-treated should be mentioned. I further suggest that other factors can be useful are storage conditions (stored at room temperature, in a refrigerator or freezer, kept in a vacuum-packed container or kept with desiccant and oxygen scavenging packets? How long was the allowable shelf-life for the component in the facility where the research was being done?)

In line with this meticulous reporting of diet treatment procedures, factors such as the heating temperatures for making diet, the duration of heating, mixing conditions such as the type of mixer and its speed. A diet mixed at $1000 \mathrm{rpm}$ 
in a steam kettle is bound to have different characteristics than a diet blended at $10,000 \mathrm{rpm}$ in a high-speed blender [3]. Likewise, particle size of solid components of diets such as lima bean meal produced in a hammer mill where a 10.0 $\mu \mathrm{M}$ sieve was used vs. a mill with a $500 \mu \mathrm{M}$ sieve was used to produce a coarse-textured meal. Cohen [3] discussed the outcome of using lima bean meal of these two extremes in a diet for Lygus spp. The fine lima bean powder milled with the $10.0 \mu \mathrm{M}$ had such a high surface to mass ratio, that the diet made from this powder bound water so tightly, that the diet had to be diluted with extra water to make the diet capable of being poured into diet feeding packets. The original diet [25] was made with lima bean meal that was made from grinding dried lima beans in a household coffee grinder. The modification made with an industrial capacity hammer mill was initially processed with a $10.0 \mu \mathrm{M}$ sieve until it was discovered that the diet failed to elicit fitness levels previously established for Lygus bugs [25]. Once the research team learned that the culprit in the rearing system deterioration was the particle size of the lima bean meal, the 500 $\mu \mathrm{M}$ sieve was substituted, and rearing production numbers soared [3]. This is an example of how a seemingly trivial aspect of a rearing system can drift inadvertently and unnoticed into unacceptable processing conditions. In well-established and highly productive research systems, hundreds of such changes or corrections must be made as was the case for the pink bollworm rearing described by Stewart [21], documented below.

The rearing technology described by Stewart 1984 [21], including the diet formulation information, remained essentially unchanged until the "game changing” paper by Edwards et al. 1996 [11]. The Phoenix pink bollworm team, led by Mr. E. Miller and the Edwards team from a USDA, Agricultural Research Food Technology Laboratory in Albany, CA joined efforts to mass-produce pink bollworm diet using state-of-the-art technology from food science: the twin-screw extruder. The Edwards et al. 1996 [11] paper describes the engineering modifications that were developed specially to produce a high-moisture product (something unusual in the conventions of food processing), and the final version of the diet (which continues to be used today).

The Edwards et al. 1996 [11] paper is an excellent example of a diet technology publication. It is significant that this paper was published in an engineering journal, rather than an entomology journal. It is of further interest that the paper has been cited only three times since its publication 20 years ago, and only one of the citations is in an entomological context (the other two in a food engineering context). This paper did not include experiments with insects, but instead the physical and chemical properties of the diets and the conditions for processing the diets are presented in excellent detail. For example, this paper provides key information about the effects of the extruder processing on thiamine content, microscopic structure of diet, texture, moisture content, and various other diet characteristics in association with processing steps. It also provides specifications of temperatures, pressures, mixing, and flow rates of diets being process by the new extruder technology. The information, as presented, is 
adequately instructive so that researchers can adopt the techniques to apply to their own diet development objectives, for other insects, for example.

So over a nearly 40 year period of pink bollworm diet development and improvement, only a sketchy treatment of the process can be found in the literature, and many of the major innovations remain undocumented or untraceable. In fact, I argue that the adoption of soy flour and the application of extruder technology are two of the most important innovations or improvements of mass-rearing systems. The topic of microbial management in pink bollworm rearing is treated in several papers including the Ouye paper and another one by Fred Stewart and his colleagues [26] (1976), but the other aspects of rearing, especially ones regarding diets, remain obscure. It is also important to note that the Challenges in Insect Rearing book edited by King and Leppla (where Stewart's chapter appears) is no longer in print, and as a USDA publication never was as available to the scientific community as are periodical publications such as ESA journals. A further fact of relevance is that the King and Leppla book is one of several government publications where rearing technology is characterized, and though the publication of diets and other rearing accomplishments helps meet some of the needs to make available discoveries that help furnish the scientific community with useful information, the recourse to only "in house" documents that lack the public attention and often lack the vetting that refereed journal provide, hinders the potential of important discoveries to reach appropriate audiences. This is not to say that the "in house" USDA publications did not do a valuable service, but the restrictions in reach to a world-wide audience must be recognized as drawbacks to expectations that the valuable information that I describe here would greatly serve the scientific community. It is also noteworthy that along with the government publications described here, there are a few monographs produced and distributed by no-government organizations such as the United Nations, FAO, and IAEA. Some of these publications present excellent explanations of rearing technology. One of the truly outstanding monographs in terms of technology of diets and other rearing components is the book on codling moth rearing by Dyck 2010 [27]. Authors would be well-served to model after the Dyck monograph their explanations of diet technology. However, for diet technology papers to be highly available for users in the rearing community, these documents need to be shorter than the nearly 200 pages of the Dyck codling moth book [28].

This leaves the specifications of how diet technology papers should be treated by authors and reviewers. I suggest as a model of technology papers, the format of a) process control and b) standard operating procedures. A framework that includes the steps in the diet-making procedure might include the protocols and standards for each step. One useful organizational scheme could be the list and specifications for the equipment and supplies used in the diet. The other part of a diet technology paper would be a presentation of the process steps from the beginning to the end of diet production. I realize that the details of this kind of approach can become excessive or they can be too sparse to be useful. However, 
a realization of the possible error-inducing outcomes makes me suggest more specification rather than less can be useful to the paper's readers. Drawing from the chapter by Stewart [21] (1984) on pink bollworm production, I will illustrate this point regarding diet processing here: 1) Diet ingredients are listed in a generic form. It would be useful to provide specific information about the specifications of diet components. For example, the Pink Bollworm Facility has developed an elegant gel strength testing process where specific amounts of agar mixed and heated in water are measured routinely whenever a new batch of agar is being considered. The Facility has a strict range of acceptable standards in terms of $\mathrm{g}$ of penetration force per $\mathrm{cm}^{2}$ required to puncture the gelled agar under standard measurement (temperature) conditions. Batches of agar that do not meet their standards (fall within the specified range) are rejected. The second ingredient listed by Stewart [21] is toasted soy flour. However, there are many soy flour products that can be considered "toasted," but they may vary in terms of the amount of toasting, mesh, whether they are defatted or re-fatted, and even protein content may vary from one brand to another. Even within brand variation is possible, and it would be helpful if the specifications were explained and if a range could be given for each possible variable. Similar comments apply to the wheat germ mentioned by Stewart as component 4 in the diet.

b) Some suggested examples of topics for technology papers:

1) Physical outcomes of processes (effects of heating on texture, mixing and particle distribution, solubility and distribution of diet components, shaping diet)

2) Chemical outcomes of processes (effects of heating or storage conditions on antioxidants, effects of heating, cooling, storage on stability of diets and diet components, interactions of diet components such as chelating agents and mineral availability) [28]

3) Container/packaging characteristics and diet qualities: gas exchange and water loss, light penetration and diet stability, containers or packaging with antimicrobial effects such as chitosan membranes for diet coating, waxes for diet coating)

4) Comparisons of conventional vs. novel materials in diets (chemical and physical comparisons of diet components such as raw vs. toasted soy flour; defatted, full-fat, re-fatted soy flour)

c) Rearing Science Papers: There are two major categories of "rearing science" papers that should be pursued: 1) rearing discoveries that were arrived at by scientific approaches and 2) basic science papers, with a rearing basis, that are applicable to the base of knowledge helpful in our enhanced understanding of the insects' biology. In the first category, the use of sound and explicitly explained rationale and hypotheses in the formulation of new or novel or improved rearing systems should be welcomed. The second category includes a wide range of scientific inquiries about such topics as insect feeding biology, reproductive dynamics (mating conditions, intricacies of the reproductive system under controlled conditions, and oviposition), developmental biology, and fea- 
tures that control diapause as a few examples of how rearing system development supports basic biology studies. As an example of the type of scientific outcomes resulting from studies using insect rearing systems, the famous geneticist and evolutionary biologist T. Dobzhansky and his research team conducted scores of studies using Drosophila species-papers that explored the genetic basis of evolution. One such study that stands as a most important demonstration of the interaction of genes (genotypes) and environmental factors is a paper by Dobzhansky and Spassky 1947 [29] where the authors used D. pseudoobscura collected from various habitats. They selected varieties (races) of $D$. pseudoobscura where there were clear genetic markers and partial chromosomal mapping available. They placed the insects in containers where there were mixtures of the different genotypes, and they held some of the containers at standard rearing temperature and other containers at lower temperatures. After several generations of the mixed rearing at "normal" and cold-stressed temperatures, the authors found that there were shifts in the population numbers of the different genotypes. This demonstrated that under controlled rearing conditions, evolutionary shifts (micro-evolution or changes in gene frequency) could be made to occur.

The diet formulation papers are the practical or applied side of insect dietetics science. The papers in this domain report formulations (often including processing practices such as use of twin-screw extruders or flash sterilizers in diet preparation) that are useful in rearing target insects. An example of the type of paper that exemplifies this approach is the Adkisson et al. 1960 [17] paper where wheat germ was introduced for rearing pink bollworms. The Adkisson et al. 1960 [17] paper meets at least some of the standards of a "scientific paper" by using a control diet (the established casein diet) and introduces wheat germ as a replacement for casein and several other components. The authors collected data on rearing outcomes with the control diet, two variable-containing diets, and even some outcomes with natural host plant. While the importance of this paper cannot be over-emphasized, I might add that it would have been even more helpful to the entomological community to have a clear statement of the rationale for using wheat germ. The authors mention that the new wheat germ diet contained fewer added ingredients than the standard: casein diet. They also point out that the wheat germ diet gave results that were equal to or superior to the standard, control diet based on casein. However, they did not explain the expectations (hypotheses) regarding wheat germ. Retrospectively, several researchers (including Erma Vanderzant) explained many of the qualities of wheat germ that helped explain its power as a keystone insect diet component, but an explicitly-stated rationale and the hypotheses stemming from the rationale (within the original paper) would have been very informative and would have helped shape mechanism-based inquiry about wheat germ in its various forms (raw, rolled, toasted, coarsely ground, finely ground, etc.) and possible substitutes for wheat germ such as various other grain products.

An important difference between diet technology papers and what I am call- 
ing rearing science papers is that the technology papers report formulations and practices that "work." That is, they are practical, and the techniques may have been developed, for example, by heuristic practices ([3] Cohen 2015). Furthermore, technology techniques should reflect data-based treatments of procedures or components that can serve as explicit process control standards. Generally, the importance of this type of treatment is overlooked or treated minimally. Even when product specifications, including brands, are reported there is often so much variability or ambiguity in diet and often other rearing system components reporting that it becomes difficult or impossible to repeat the conditions that shaped the original findings. Many examples of this are available, but one of the most striking is in ambiguities of the common insect diet components such as soy products.

d) Some suggested examples of topics for rearing science papers:

1) Scientifically-based rearing systems

a) Topics are based on explicitly-stated rationale and hypotheses

b) Experimental designs are grounded in comparisons of rearing components, sub-systems and processes

2) Science behind rearing system development and evaluation

a) Application of Design of Experiments approaches to rearing system optimization (engineering-based statistical quality/process control)

b) Nutritional characteristics and value of foods and diet components (classical nutritional studies)

c) Nutrient self-selection and related studies

d) Feeding behavior (responses to sensory stimuli, behavior of mouth parts, etc.)

e) Digestive or other feeding-related enzymes

f) Analysis of insects' foods (chemical and physical analysis)

g) Bioavailability determinations of various natural and artificial foods

h) Factors that contribute to diet stability (antimicrobial materials, antioxidants, emulsifiers, etc.)

i) Effects of lighting features (intensity, quality, photoperiod) on diapause, growth profiles, and other biological factors

j) Studies of micro-environment in rearing systems (thermal and humidity gradients, gas transfer in rearing containers, and insectary design modelled after nature

k) Microbial relationships in insects from rearing systems (microbiome analysis in relation to rearing conditions)

1) Genetic relationships to rearing conditions: studies of deliberate and inadvertent domestication.

m) Other studies of diet component and processing functionality

\section{Eleven Suggestions for Enhancing Rearing Publications from Cohen 2001 [4]}

In 2001, Cohen [4] discussed several approaches to establishing a formal status 
for insect rearing. He included several suggestions for improvements in rearing papers. The suggestions from the earlier paper are in italics, and my updated suggestions follow.

1) Whenever possible, studies should be experiment-based, centered on hypothesis/control/variable methodology. This statement is the basis of proposing the insect rearing papers should be science-based. Too many papers on insect rearing are anecdotal or not rationale- and hypothesis-driven. Important factors in making rearing papers better contribute to scientific understanding are attention to mechanisms behind experimental outcomes, properly designed and controlled experiments, and attention to interactions of rearing systems' components-especially factors that are part of the rearing experiments that are the subjects of intended publications. This implies that observations and measurements are included in the experiments, and the data from these measurements is a powerful tool in evaluating the experimental outcomes and sources of error that can be reduced to improve rearing outcomes. These topics are important components in the following suggestions about experimental design and statistics, quality and process control, and explicit statements of rationale.

2) Appropriate experimental design and statistics should be used. This point goes hand-in-hand with and is an outgrowth of Suggestion 1. In today's scientific world, Design of Statistics procedures are available to every researcher, with some statistical packages being available free, while other statistical systems are available on institutional levels. Currently, exploratory statistics are becoming a well-established tool, and these statistical approaches help researchers with less sophisticated statistical backgrounds to take advantage of elegant experimental designs and interpretational algorithms. This includes, for example, mixture designs, full-factorial and partial factorial designs, and other approaches that allow screening designs, response surface designs, and space-filling designs. These packaged experimental designs include quality and process control approaches that lend themselves tremendously to development and improvement of insect rearing systems (Cohen 2015).

3) Quality control or quality assessment should be a clear-cut and integral part of the reports. Quality control (QC) and process control (PC) have become common factors in mass-rearing systems where millions to billions of insects are produced routinely (Cohen 2015). Statistically-based QC and PC standards have been adopted in large-scale insectary operations to make quality and process standards part of continuous improvement programs and a basis of meeting needs of customers of the rearing products. However, these standards are adopted late in the process of mass-rearing system development, and it would not only be useful to more seamless adoption of quality/process standards, but preliminary (or early) research works would also be enhanced by adoption of data acquisition and data analysis that helped researchers determine the sources and extent of variation in their incipient research system. For example, a control chart showing the upper and lower control limits of temperature or protein content of a diet component could be a powerful and highly documentable measure 
of the quality of a foundational experiment.

4) Proper citation of past progress should be made along with a clear statement of how the paper in question advances the previous state of knowledge. Far too many rearing papers treat background as a "given" that does not need to be discussed or documented by reference to past works. Admittedly, this is a difficult issue for authors and reviewers to deal with, as there are so many facets of rearing studies that are involved in the rearing process. If a rearing component is conventional, it is reasonable to omit specific, part-by-part references. However, authors of rearing papers should be careful to review the background for the processes that they include in their rearing studies, and if a process or material is central to the experimental questions that the paper is exploring or if the experiments adopt a novel concept from a published source, the author(s) of that publication should be cited.

5) Clearly and deliberately stated rationale should be made for every novel facet of the work. This is closely related to Suggestion 1, both being concerned with mechanistic-driven, science-based studies. This point relates to the rationale for the experimental components of rearing research projects. Rearing papers would be far more valuable if they were always predicated upon explicitly stated rationale. Most of the rearing innovations that have proved to be successful have a scientific, mechanistic reason for their success. While it is true that many rearing factors are so complex or otherwise difficult to unravel, the quest to understand why things work should always be a goal of rearing researchers. However, too often rearing papers are treated by authors, reviewers, and editors as being only of practical or heuristic value. This adds a black-box or mystical character to rearing advancements. These two suggestions (4 and 5) bring into focus the value of stating rationale for rearing advancements as well as citation of past sources. When the author of [30] introduced a suite of techniques that made mass-rearing of tobacco hornworms possible, he stated rationale for the types of containers, diet-holding platforms, and various other physical features of the rearing system that allowed healthy reproduction by the captive hornworm adults. When the same author introduced a diet for larvae of the tobacco hornworm [31] introduced a diet for these insects, he revolutionized the rearing of these and many other insects. However, two of the main components of the diet, wheat germ and torula yeast, remain an enigma. The author did not cite the original source of the wheat germ in the hornworm diet, though the paper published by another group of authors [17] was most likely the original source of the idea of using wheat germ. It would have been helpful to the readers to know that the addition of wheat germ was originated as an extension of the earlier paper, and it would have added further stature to the paper and its authors who clearly deserved citation. The other issue, the use of torula yeast, is an enigma to me because this material clearly works well (as proved by the hundreds of generations of hornworms reared on this diet), yet there is no stated rationale for why torula was chosen in light of the several other papers published prior to [30] and [31] where brewer's yeast was used as a nutrient source. 
6) Editors, reviewers, and people who judge rearing accomplishments (e.g., promotion and tenure committees) should be made aware of the painfully long and high-risk nature of these advancements, and they should judge them accordingly. This point addresses the tendency of the audience of rearing papers to expect that all accomplishments worthy of publications to be saltatory, rather than incremental, advancements. When the early papers in Drosophila rearing appeared, they were inherently novel, ground-breaking studies. In the early 1900s, the use of controlled rearing systems and artificial diets [5] [6] [7] [12] [13] [14] and [15], the introduction of yeast to Drosophila diets [5] [12] and [14], and the introduction of agar-based diets [13] were entirely novel, and the early rearing systems described in those papers (cited here) were clearly saltatory advancements. When wheat germ was added to Lepidoptera diets [16] and [17], this was a major advancement that sent ripples throughout the domain of insect rearing. However, when wheat germ was included for the first time in a diet for the tobacco hornworm, Manduca sexta, [30] and [31] this was by its inherent nature an incremental accomplishment, but it had huge ramifications in influencing rearing systems for other insects and for the vast amount of research and production based on the $M$. sexta rearing technology.

7) A clear distinction should be made between insect dietetics and nutrition. Works in both domains should be welcomed. Because nutrition has long been an established science with inherently mechanistic and experimental basis, when applied to insects, it was automatically respected and regarded as a true science. Conversely, because the word "diet" has had use in day-to-day discussions of foods in the context of cooking and other uses where there was not necessarily scientific rigor, insect dietetics has been relegated to a position of lesser respect. Even the often-used term for diet formulations as "recipe" induces the users of the term and the audience to regard diet formulation as a non-scientific process. One often hears diet specialists and their audience referring to "tweaking" an established diet, which connotes making minor, often trivial changes in a diet or other features of a rearing system. My argument is that nutrition studies deserve respect and a place in the publication of science and technology studies, but dietetics should also be treated scientifically and should, likewise, have a respected place in literature on insect rearing.

8) The problems incumbent in insect rearing as a service field should be recognized and addressed. This is not especially a standard for publication, but it is instead a background concept that needs serious attention. The history of rearing systems development has shown that the practical goal of establishing parameters that Delcourt and Guyenot developed in 1910 [5] involve control over the production of insects for various purposes (Figure 1). This is the heuristic concept of insect rearing as contrasted with the scientific concept where one seeks to understand the rationale behind and interactions between rearing system components. This contrast is tantamount to establishing a rearing system in order to produce insects vs. the discovery-based system of understanding the insects through manipulation and controlled rearing inquiries (Figure 2). There 


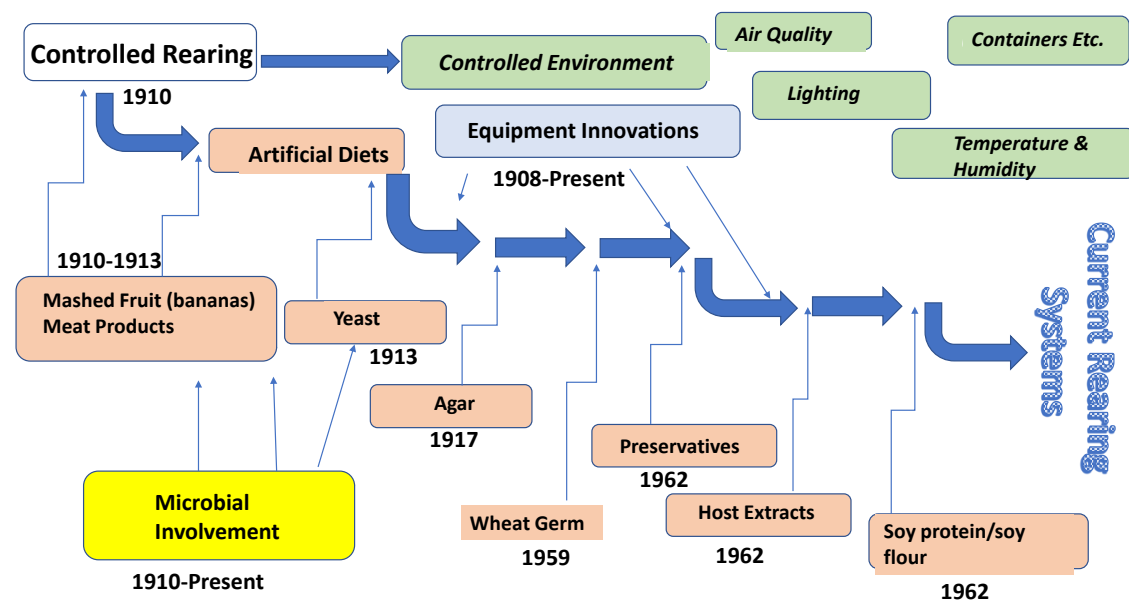

Figure 1. Historical Background for Current Rearing Systems. Each innovation represented here evolved into a fundamental part of modern insect rearing technology. Many contributions such as the initial introduction of wheat germ or adoption of preservatives was viewed as an incremental contribution. However, many seemingly incremental advancements became giant leaps in the progress of rearing science and technology.
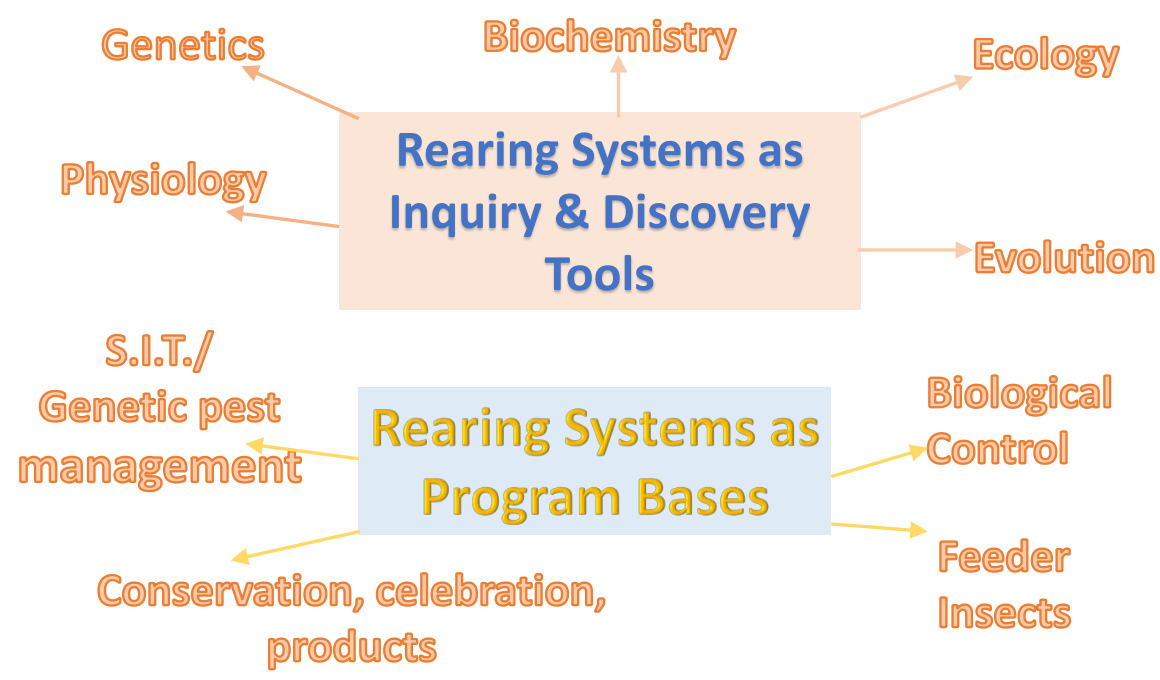

Figure 2. Functions of Insect Rearing Systems. Throughout their history and development insect rearing systems have been used initially for tools of discovery for various basic biological sciences and later as the bases of various programs where mass-rearing serves purposes such as control or sources of insect products.

are many examples that illustrate the concept here, but the emergence of the science of genetics stemming from the practical, heuristic field of plant or animal breeding makes the point. People were developing strains or breeds of plants and animals (such as domesticated wheat or dog breeds) long before the science of genetics emerged in the late 1900s. The development of genetics as a science did nothing but enhance the breeding efforts and allowed remarkably useful domestic organisms on a continuing basis. So it would be with insect rearing, if rearing experts were given an "open license" to treat rearing studies with scientific principles and rigor. 
9) Specific formal education in rearing science and technology should be established. Since I entered the field of insect rearing around 1980, I have been trying to establish a system of formal education to help existing and emerging rearing specialists to have better tools to use for inquiry and discovery of rearing system components. I have been teaching classes, helping to establish workshops, and writing papers to help improve the formal education infrastructure. I have pointed out that thus far, all of us who consider ourselves as rearing experts or rearing professionals have had to learn most of our knowledge and understanding through trial-and-error, on the job training, and somewhat haphazard experiences with insect rearing literature. While this can be a complex discussion, suffice it to say that a well-designed formal system of rearing education would greatly expedite all aspects of rearing, including the quality and scope of insect rearing publications. At North Carolina State University (Department of Entomology and Plant Pathology), we have been offering courses in the principles of insect rearing science and technology. In these courses, we emphasize the importance of explicit expression of rationale and hypotheses that rearing research should employ. Figure 3 shows students from several of the courses, and what is conveyed by this figure is that this effort at rearing education emphasizes hands-on experiences where students are encouraged to conduct inquiries and efforts at discovery, then they write reports (mini-publications) that encourage students to conduct appropriate and critical search and scrutiny of the literature. It has been my experience with these inquiry and rational-centered exercises, students have a much deeper appreciation and ability to connect rearing studies and deeper understanding of insects.

10) A specific, special section in insect rearing science and technology should be added to at least one of the ESA [Entomological Society of America] journals. This point is somewhat self-explanatory, and I now recommend that the idea of specialized sections of journal (possibly a rearing-specific journal) with the explicit title of "insect rearing systems" would be a worthwhile addition to the field of entomology. Later in this paper, I will treat more explicitly what strategies could be employed to welcome studies of insect rearing systems.

11) A formal sub-discipline encompassing insect food science and technology should be established with a place for publications in this special field in one of the ESA journals. These two points (Suggestions 10 and 11) are aimed at the largest international association of entomologists and one of the longest-standing sources of insect rearing publications. I discuss elsewhere [2] how the ESA publication (Journal of Economic Entomology) has been one of the leading publishers of papers on insect rearing since the journal's inception in 1908; however, at the same time, it has been very restrictive in its treatment of insect rearing papers. My argument in [2] [3] and [4] is that if ESA journals and various other publications (especially open-access publications) would establish a systematic and clear-cut set of standards for rearing papers such as the ones offered here, the quality of rearing publications and the research behind these publications would be greatly improved. I further argue that with the more open 


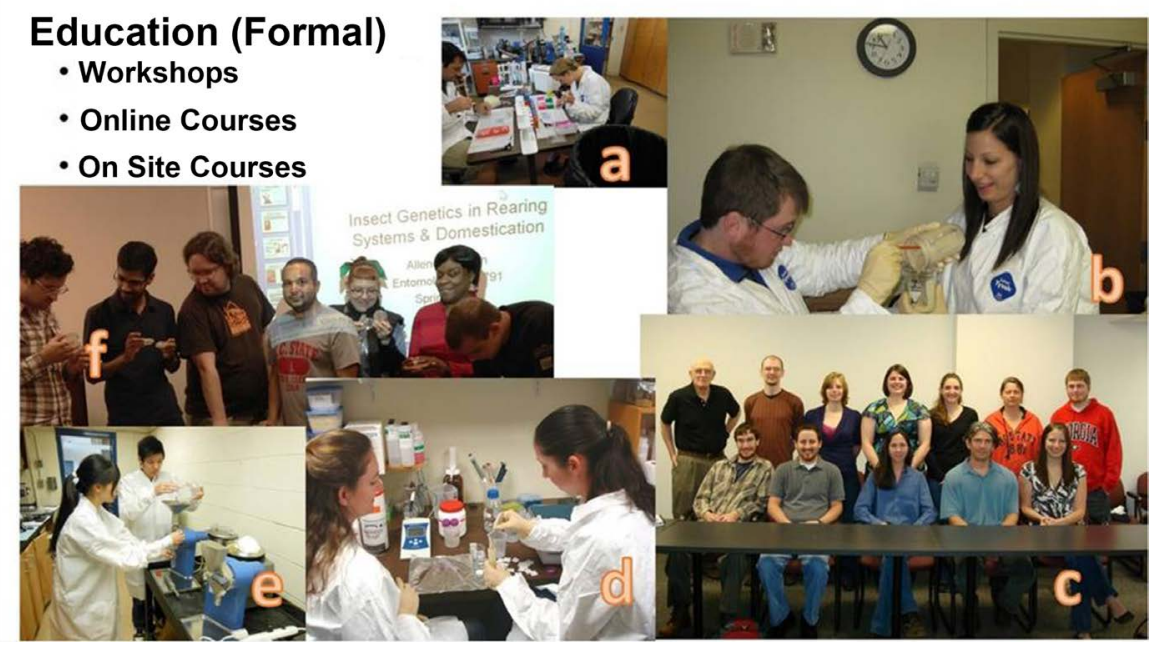

Figure 3. On-site Classes in Insect Rearing at North Carolina State University (NCSU). Students are shown in classrooms and labs, performing rearing experiments, learning the principles of insect rearing and approaches to write science-based rearing papers. Figure 3(a): David Bednar (left) and Mary Talley (right) working on protein analysis of hemlock woolly adelgids. Figure 3(b) Micah Gardner (left) and Kelly Oten (right) synthesizing lacewing diets. Figure 3(c): the first (2011) class in insect rearing at NCSU: bottom row left to right: John Hanley, Jonathan Cammack, Alana Jacobson, Rick Santangelo, Kelly Oten Top row left to right: Allen Cohen, Andrew Ernst, Amy Lockwood, Michelle Meck, Nancy Brill, Heather Moscrip, and Micah Gardner. Figure 3(d): Nancy Brill (left) and Alana Jacobson (right) making a prototype diet for thrips. Figure 3(e): Pei-Shan Wu (left) and $\mathrm{Fu}-\mathrm{Chyun} \mathrm{Chu}$ (right) preparing corn seedling extracts for a corn rootworm diet. Figure 3(f): Students in Rearing Courses at NCSU (top, 2015 rearing class, bottom right 2011 rearing class) (Top left: Nick Travanty, Arun Babu, Robert Mitchel, Anirudh Dhammi, Synda McCracken, Folukemi Adedipe (Kemi), Forrest Howell.

attitude towards rearing studies, the field would blossom, and would undergo a renaissance of learning and enlightenment about insects rearing under the controlled conditions of insect rearing systems.

\section{Case Studies that Exemplify Significant Rearing Contributions}

Many of the earliest rearing papers that helped launch the field of insect rearing provide excellent models for the kinds of papers that should be published to report advances in the science and technology of rearing. The inauguration of the design concept from the 1910 paper by Delcourt and Guyenot [5] was already discussed, as were Drosophila-rearing papers by Baumberger [12] [13] and Guyenot [14] [15]. Other papers that are excellent models of rationale-based rearing research on Drosophila and other Diptera include [32] where Baumberger provides a useful review of papers in the first two decades of the $20^{\text {th }}$ Century dealing with the possible roles of microbes in the natural history and rearing dynamics of insects. In an extensive thesis on nutritional issues in flesh flies, Michelbacher et al. [33] takes up the issues raised by Bogdanov [6] [7] regarding the interplay between nutritional ecology of insects (especially Diptera) 
and the microbial associations that are intimately associated with insects from this order. Both Baumberger [32] and Michelbacher et al. [33] discuss the rationale for experimentally teasing apart the questions of live vs. dead microbes and the changes in the nutritional composition rendered by the microbial actions. The questions of the nutritional value of the media (such as flesh or fruit) vs. the nutritional value of the microbes vs. the metabolic (fermentation) products of the microbes and the media remain a complex and incompletely understood relationship today.

Other cases of highly informative discussions of rationale for various refined experimental details are found in the papers of Loeb [34] [35] Burgess 1908 [36] and Bridges [37] and Bridges and Darby [38]. Loeb reported studies where he tried to determine the minimal requirements of an insect, in terms of the simplest possible nutrient composition of a diet. He used salts and a source of nitrogen (an ammonium compound) and initially reported success in rearing Drosophila on such a simple media. He later discovered that his culture was contaminated by microbial growth, and that it was the microbial colony that had supported his insects' growth and development. These flawed experiments became the subject of many illuminating discussions discussed by several other authors. Burgess [36] wrote the first paper on various devices used for rearing insects. Apparently, many of the cages, lighting systems, and other rearing system components were in use by the time Burgess' paper was written, but these methods had not been documented in the literature and Burgess was the first to do so, though the detailed methods for materials, equipment, and design remain largely neglected in the literature.

In terms of valuable, detailed rationale for rearing system engineering or design, one of the most impressive treatises is from Calvin Bridges, who is known for the work he did in the pioneering genetics studies in the T. H. Morgan genetics laboratory (see Morgan [39]) where A. H. Sturtevant, H. J. Muller, and Calvin Bridges worked in the famous "Fly Room" at Columbia University through the early decades of the 1900s until the 1930s. For example, to explain the details of a prototype incubator, Bridges 1932 wrote:

"DURING the early work on the genetics of Drosophila melanogaster the cultures were reared on laboratory tables or on open wall shelving. This method gave irregular results. The cold nights of the winter season made a considerable proportion of the cultures fail to start properly, and also lengthened the generation interval.

"In 1913 I built above my laboratory table a large wooden incubator which held all my experimental cultures. This incubator was heated by carbon electric lamps placed in the lowest shelf space. The thermostat was of the "ether-wafer" type. The expansion of the ether forced apart contacts in the heating circuit. A six-inch electric fan continuously circulated air down a gap behind the shelving with return through a similar gap between the shelves and the doors." 
Elsewhere, Bridges explained the importance of temperature regulation in rearing circumstances-that it was crucial for uniformity, and to help control the very genetic factors that Drosophila researchers were trying to determine. $\mathrm{He}$ pointed out that linkage/crossover studies are skewed by deviations in temperature. Bridges wrote, "Plough's work on the effect of temperature extremes on crossing-over showed that it was necessary to maintain the temperature constant for genetic reasons as well as to improve culture conditions." Unfortunately, the recognition of the far-reaching effects of temperature and other facets of rearing is lost in terms of the consequences of lack of control of rearing conditions. Bridges and Darby [38] discussed the details of diet development, which they document as one of the most important advancements to assure reliability and certainty to the genetic tests whose outcomes provided the base of modern genetic science.

The points that Bridges made about the importance of temperature in rearing system outcomes has been reaffirmed in numerous studies ([40]-[46]). In these studies topics ranging from relationship of temperature to development rate, metabolic efficiency, and fitness of reared insects, in general. These studies were excellent models of the discoveries of basic biological principles that were made possible by having controlled rearing conditions. In a recent study in my own laboratory, we discovered that greater wax moth larvae (Galleria mellonella: Pyralidae: Lepidoptera) were capable of generating their own heat and raising their body temperature and that of their larval aggregation mass by up to $10^{\circ} \mathrm{C}$ (Figure 4). These types of discovery of temperature relations, metabolic phenomena, and other basic science is made possible or more accessible in rearing systems, and such discoveries are worthy of publication in the context of basic and applied science.

Many other discoveries pertaining to diet (such as Shorey [47] [48]) and diet preparation [49] [50] expand the horizons of diets in rearing systems. These discoveries and test results characterize novel components that are disparate from the insects' natural diets and they offer processing techniques that have made possible rearing insects that could not be cultivated without these advancements. The advancements reported by Shorey, who introduced use of pinto beans and lima beans, were the basis of later efforts by Alfazairy et al. [51] to use legumes and whole rice to replace gelling agents such as agar to confer appropriate texture to insect diets. Ever since Baumberger's landmark introduction of agar as a gelling agent in Drosophila diets, agar or agar replacements such as carrageenan or alginate have been one of the most expensive and yet troublesome components of insect diets [3] [52]-[56]. The major point of this discussion is that too many worthwhile contributions to improve insect rearing go unpublished or published in obscure places due to a lack of clear structure for treating novel, useful rearing contributions. This failing needs to be corrected by a concerted effort in the rearing community and the entomological community served by rearing specialists to welcome rearing contributions to the body of literature and communication. 


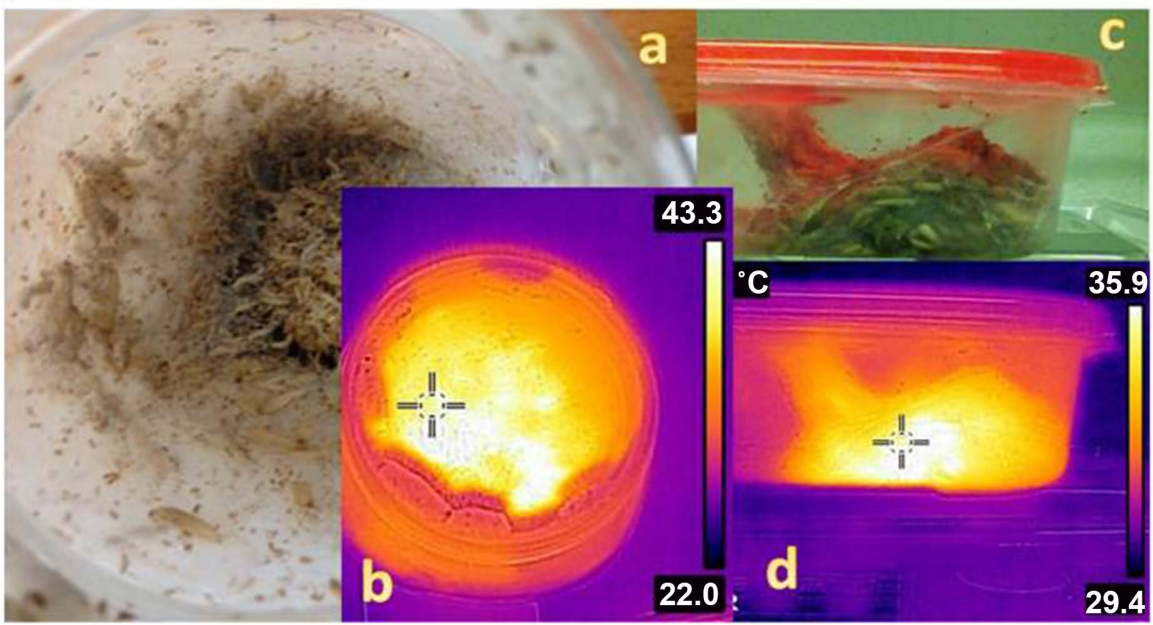

Figure 4. Wax Moth Thermogenesis in Rearing Containers. Figure 4(a) and Figure 4(b) are views through the top of a 2 liter glass jar (Figure 4(a) being a visual light image, Figure 4(b) being a thermal image, showing the elevated temperatures generated by larval masses). Figure 4(c) and Figure 4(d) are images from a plastic (Rubbermaid ${ }^{\mathrm{TM}} 3$ liter container). Figure $3(\mathrm{c})$ is a visible light image, and Figure $4(\mathrm{~d})$ is a thermal image showing the webbing and frass-covered mass teeming with larvae. The organization of the larval colony is typical of how the larvae spin webbing as scaffolding leading to the top of the container giving them access to fresh air.

\section{Welcoming Rearing Advancements in the Literature}

Throughout the body of this paper, I have tried to express the importance of various rearing contributions towards the science and technology of insect programs. I have tried to express the dilemma of what sometimes seemed incremental or even trivial contributions being excluded from the literature of insect science and technology. Yet many of these contributions have proven themselves to be "game-changers" for more conspicuous discoveries or scientific landmarks (such as most of modern genetic knowledge and how dependent this body has been on ability to rear Drosophila). I have further pointed out that in the earlier years of insect rearing and the science and technology supported by rearing capabilities, many rearing contributions were highlighted in the most prestigious journals. However, the trend over the past five or six decades has been to downplay the value of publishing rearing advancements and innovations.

This leads to the point about welcoming rearing papers. Norm Leppla addressed this issue back in 1978 [57] when he made efforts to establish in ESA journals a special place for entomological techniques. This issue was discussed by Cohen [3] who wrote that there were difficulties in getting rearing papers published in ESA journals and other publications. In Leppla's words,

We are all aware of the tremendous financial investment and unfortunate duplication of effort that are involved in pursuing technological research. Yet, it is often difficult to publish techniques and practically impossible to retrieve information on techniques that is buried in methods sections or relatively obscure journals. Apparently a paradox exists. If this work is 
worth doing, it should be communicated. Otherwise, it should be replaced by more important endeavors.

What contributed to Leppla's argument was a survey taken in 1977 regarding the problems that entomologists had with publishing rearing papers. Of the 50 respondents in that survey 25 wanted to have a rearing section in one or more of the ESA journals, 14 wanted subject specialists to review papers, and two wanted a special annual bibliography of categorized techniques abstracted from methods sections of rearing articles.

In summation, Cohen [3] included other points made by Leppla that "consultation with specialists in each subdiscipline to allow papers on insect rearing to '...be processed with the same consideration as other more 'prestigious' subjects,' and 'maintain or raise existing standards of excellence but avoid rejection of manuscripts merely because they contain results that contradict established concepts." Although, these standards were temporarily adopted, the situation quickly revered to the original one where rearing papers were treated in an inconsistent and too often hostile manner. It remains an irony that and The Journal of Economic Entomology, which published a rearing paper in 1908 by Burgess [36] in its first volume. Yet the following statement is the response that my coauthor and I received from an editor of the Journal of Economic Entomology after we submitted a paper on responses of a plant bug (Lygus hesperus) to various antimicrobial agents [58]:

"I have only received one review of your manuscript to date. Because the review process has taken so long, I am going to go with this review only. The reviewer recommended that your manuscript be accepted after major revision. I too have read your paper and have made some comments on the copy labeled 'editor's comments.' The major problem with your paper is that it deals with insect diets and unfortunately the Journal of Economic Entomology does not publish diet studies. In fact, I just returned two papers without review to two other authors because they dealt with the effects of differences in diet components. However, your paper is really about the toxicology of components of insect diets. I feel that the way to get around the diet issue is to de-emphasize the diet aspect of your study and emphasize the toxicology aspects. This is just a matter of wording."

The paper in question [58] was ultimately published and has been cited more than 30 times and serves as a model for evaluating fitness of insects in response to diet preservatives. I have included this editor's comments because they state the quasi-official policy to not welcome papers on diets or other rearing topics. I used this quotation as one of many that I have received in my career in insect rearing/insect diet development. This experience is common to researchers who try to publish their work on insect rearing.

There are several measures that can be taken for rearing papers to be allowed to take their place as valid science/technology contributions to entomology. 1) 
Entomology journals must deliberately establish a policy of inclusion of all types of rearing papers as long as the science and/or technology is sound. 2) The journals that have established the policy of acceptance must include in their statements of policy that rearing papers that are scientifically or technologically sound will be welcomed by the journals' editors. 3) The journals that welcome rearing papers must assure that their editors are open to seeking reviewers who have subject area expertise in rearing. As a former editor of two major journals, I know that developing a list of rearing experts to serve as reviewers, I realize that finding a critical mass of such experts is a difficult but not impossible task. 4) The journals in question should provide standards and guidelines for authors, editors and reviewers of the high standards that the journal expects for rearing papers. 5) The journals that welcome rearing papers need to take strong, deliberate measures to rectify the situation where prejudice against rearing research/discovery has become the established tenor. These measures to normalize the process of communicating rearing advancements will serve to model the process of sound research approaches (as explained in the body of this paper), and these efforts will lead to improvements in the quality of rearing papers by serving as models that can establish rearing as a well-respected branch or sub-discipline of entomology.

\section{Conflicts of Interest}

The author declares no conflicts of interest regarding the publication of this paper.

\section{References}

[1] Cohen, A.C. (2018) Ecology of Insect Rearing Systems: A Mini-Review of Insect Rearing Papers from 1906-2017. Advances in Entomology, 6, 86-115. https://doi.org/10.4236/ae.2018.62008

[2] Cohen, A.C. (2018) Infrastructure of Insect Rearing. American Entomologist. Submitted.

[3] Cohen, A.C. (2015) Insect Diets: Science and Technology. 2nd Edition. CRC Press, Boca Raton, Fl. https://doi.org/10.1201/b18562

[4] Cohen, A.C. (2001) Formalizing Insect Rearing and Artificial Diet Technology. American Entomologist, 47, 198-206. https://doi.org/10.1093/ae/47.4.198

[5] Delcourt, A. and Guyenot, E. (1910) The Possibility of Studying Certain Diptera in a Defined Environment. Comptes rendus hebdomadaires des séances de P Académie des sciences (0001-4036), 151, 255-257.

[6] Bogdanow, E.A. (1906) About the Breeding of Larvae in Usual Flesh Flies (Calliphora vomitoria) in Sterilized Nutrients. Archiv für die gesamte Physiologie des Menschen und der Tiere, 113, 97-105. https://doi.org/10.1007/BF01677331

[7] Bogdanow, E.A. (1908) About the Dependence of the Growth of Larvae of Bacteria and Enzymes and about Variability and Inheritance in the Flesh Flies. Archiv fur Anatomie, Physiologie und Wissenschaftliche Medicin, Suppl., 1908, 173-200.

[8] Dethier, V.G. (1976) The Hungry Fly: A Physiological Study of the Behavior Associated with Feeding. Harvard University Press, Cambridge, MA. 
[9] Hamamura, Y. (1959) Food Selection by Silkworm Larvae. Nature, 183, 1746-1747. https://doi.org/10.1038/1831746a0

[10] Hamamura, Y. (2001) Feeding Mechanisms and Artificial Diet of Silkworms; Research Records on Feeding and Growth in Silkworms. In: Hamamura, Y., Ed., Silkworm Rearing on Artificial Diet, Science Publishers, Inc., Enfield, New York, 3-32, 33-68. (In Japanese)

[11] Edwards, R.H., Miller, E., Becker, R., Mossman, A.P. and Irving, D.W. (1996) Twin Screw Extrusion Processing of Diet for Mass Rearing the Pink Bollworm. Transactions of the ASAE, 39, 1789-1787. https://doi.org/10.13031/2013.27655

[12] Baumberger, J.P. (1917) The Food of Drosophila melanogaster Meigen. Proceedings of the National Academy of Sciences of the United States of America, 3, 122-126. https://doi.org/10.1073/pnas.3.2.122

[13] Baumberger, J.P. (1917) Solid Media for Rearing Drosophila. American Naturalist, 51, 447-448. https://doi.org/10.1086/279622

[14] Guyenot, E. (1913) Biological Study in a Fly, Drosophila ampeltophila Low II-The Role of Yeast in Food. Comptes Rendus des Seances de la Societe de Biologie et de Ses Filiales, 74, 178-180.

[15] Guyenot, E. (1914) Biological Studies on a Fly Drosophila ampelophila Low. Need to Create a Definite Feeding Environment. Comptes rendus des séances de la Société de biologie et de ses filiales (0037-9026), 76, 483-485.

[16] Vanderzant, E.S., Richardson, C.D. and Davich, T.B. (1959) Feeding and Oviposition by the Boll Weevil on Artificial Diets. Journal of Economic Entomology, 52, 1138-1142. https://doi.org/10.1093/jee/52.6.1138

[17] Adkisson, P.L., Vanderzant, E.S., Bull, D.L. and Allison, W.E. (1960) A Wheat Germ Medium for Rearing the Pink Bollworm. Journal of Economic Entomology, 53, 759-762. https://doi.org/10.1093/jee/53.5.759

[18] Assemi, H., Rezapanah, M., Vafaei-Shoushtari, R. and Mehrvar, A. (2012) Modified Artificial Diet for Rearing of Tobacco Budworm, Helicoverpa armigera, Using the Taguchi Method and Derringer's Desirability Function. Journal of Insect Science, 12, 100. http://www.insectscience.org/12.100 https://doi.org/10.1673/031.012.10001

[19] Lapointe, S.L., Evens, T.J. and Niedz, R.P. (2008) Insect Diets as Mixtures: Optimization for a Polyphagous Weevil. Journal of Insect Physiology, 54, 1157-1167. https://doi.org/10.1016/j.jinsphys.2008.04.020

[20] Lund, M.E. and Parrella, M.P. (2015) Crickets Are Not a Free Lunch: Protein Capture from Scalable Organic Side-Streams via High-Density Populations of Acheta domesticus. PLoS ONE, 10, e0118785. https://doi.org/10.1371/journal.pone.0118785

[21] Stewart, F.D. (1984) Mass Rearing the Pink Bollworm, Pectinophora gossypiella. In: King, E.G. and Leppla, N.C., Eds., Advances and Challenges in Insect Rearing, USDA, ARS, New Orleans, 176-187.

[22] Ouye, M.T. (1962) Effects of Antimicrobial Agents on Micro-Organisms and Pink Bollworm Development. Journal of Economic Entomology, 55, 854-857. https://doi.org/10.1093/jee/55.6.854

[23] Redfern, R.E. (1963) Concentrate Media for Rearing Red-Banded Leaf Roller. Journal of Economic Entomology, 56, 240-241. https://doi.org/10.1093/jee/56.2.240

[24] Shaver, T.N. and Raulston, J.R. (1971) A Soybean-Wheat Germ Diet for Rearing the Tobacco Budworm. Annals of the Entomological Society of America, 64, 1077-1079. 
https://doi.org/10.1093/aesa/64.5.1077

[25] Cohen, A.C. (2000) New Oligidic Production Diet for Lygus hesperus Knight and L. lineolaris (Palisot de Beauvois). Journal of Entomological Science, 35, 301-310. https://doi.org/10.18474/0749-8004-35.3.301

[26] Stewart, F.D., Bell, R.B., Martinez, A.J., Roberson, J.J. and Lowe, A.M. (1976) The Surface Sterilization of Pink Bollworm Eggs and Spread of Cytoplasmic polyhedrosis Virus in Rearing Containers. U.S. Anim. Plant Health Insp. Serv., 81-27.

[27] Dyck, V.A. (2010) Rearing Codling Moth for the Sterile Insect Technique. Food and Agriculture Organization of the United Nations. FAO Plant Production and Protection Paper 199, Rome.

[28] Cohen, A.C. and Crittenden, P. (2004) Deliberately Added and "Cryptic" Antioxidants in Three Artificial Diets for Insects. Journal of Economic Entomology, 97, 265-272. https://doi.org/10.1093/jee/97.2.265

[29] Dobzhansky, Th. and Spassky, B. (1947) Evolutionary Changes in Laboratory Cultures of Drosophila pseudoobscura. Evolution, 1, 191-216. https://doi.org/10.1111/j.1558-5646.1947.tb01338.x

[30] Yamamoto, R.T. (1968) Mass Rearing of Tobacco Hornworm: 1 Egg Production. Journal of Economic Entomology, 61, 170-174. https://doi.org/10.1093/jee/61.1.170

[31] Yamamoto, R.T. (1969) Mass Rearing of Tobacco Hornworm: 2 Larval Rearing and Pupation. Journal of Economic Entomology, 62, 1427-1431. https://doi.org/10.1093/jee/62.6.1427

[32] Baumberger, J.P. (1919) A Nutritional Study of Insects, with Special Reference to Microorganisms and Their Substrata. Journal of Experimental Zoology, 28, 1-81. https://doi.org/10.1002/jez.1400280102

[33] Michelbacher, A.E., Hoskins, W.M. and Herms, W.B. (1932) The Nutrition of Flesh Fly Larvae, Lucilia sericata (Meig.). Journal of Experimental Zoology, 64, 109-131. https://doi.org/10.1002/jez.1400640107

[34] Loeb, J. (1915) The Simplest Constituents Required for Growth and the Completion of the Life Cycle in an Insect (Drosophila). Science, 41, 169-170. https://doi.org/10.1126/science.41.1048.169

[35] Loeb, J. and Northrop, J.H. (1917) On the Influence of Food and Temperature on the Duration of Life. Journal of Biological Chemistry, 32, 103-121.

[36] Burgess, A.F. (1908) Description of New Devices for Rearing Insects. Journal of Economic Entomology, 1, 267-269. https://doi.org/10.1093/jee/1.4.267

[37] Bridges, C.B. (1932) Apparatus and Methods for Drosophila Culture. The American Naturalist, 66, 250-273. https://doi.org/10.1086/280430

[38] Bridges, C.B. and Darby, H.H. (1933) Culture Media for Drosophila and the pH of Media. The American Naturalist, 67, 437-472. https://doi.org/10.1086/280505

[39] Morgan, T.H., Sturtevant, A.H., Muller, H.J. and Bridges, C.B. (1913) The Mechanism of Mendelian Heredity. Henry Holt and Company, New York.

[40] Butler, G.D. (1966) Development of Several Predaceous Hemiptera in Relation to Temperature. Journal of Economic Entomology, 59, 1306-1310. https://doi.org/10.1093/jee/59.5.1306

[41] Smith, R.C. (1931) A Study of Temperature and Humidity Conditions in Common Types of Insect Rearing Cages. Journal of Agricultural Research, 43, 547-557.

[42] Stinner, R.E., Gutierrez, A.P. and Butler, G.D. (1974) Algorithm for Temperature-Dependent Growth-Rate Simulation. Canadian Entomologist, 106, 519-524. 
https://doi.org/10.4039/Ent106519-5

[43] Butler, G.D., Henneberry, T.J. and Clayton, T. (1983) Bemisia-Tabaci (Homoptera, Aleyrodidae) - Development, Oviposition, and Longevity in Relation to Temperature. Annals of the Entomological Society of America, 76, 310-313. https://doi.org/10.1093/aesa/76.2.310

[44] Visscher, S.N., Lund, R. and Whitmore, W. (1979) Host Plant-Growth Temperatures and Insect Rearing Temperatures Influence Reproduction and Longevity in the Grasshopper, Aulocara elliotti (Orthoptera, Acrididae). Environmental Entomology, 8, 253-258. https://doi.org/10.1093/ee/8.2.253

[45] Manel, S. and Debouzie, D. (1997) Modeling Insect Development Time of Two or More Larval Stages in the Field under Variable Temperatures. Environmental Entomology, 26, 163-169. https://doi.org/10.1093/ee/26.2.163

[46] Sprugeon, D.W. and Brent, C.S. (2016) Development, Survival, and Hatching Periodicity of Lygus hesperus (Hemiptera: Miridae) Eggs under Constant and Variable Temperatures. Journal of Entomological Science, 51, 292-304.

https://doi.org/10.18474/JES16-17.1

[47] Shorey, H.H. (1963) A Simple Artificial Rearing Medium for the Cabbage Looper. Journal of Economic Entomology, 56, 536-537. https://doi.org/10.1093/jee/56.4.536a

[48] Shorey, H.H. and Hale, R.L. (1965) Mass-Rearing of the Larvae of Nine Noctuid Species on a Simple Artificial Medium. Journal of Economic Entomology, 58, 522-524. https://doi.org/10.1093/jee/58.3.522

[49] Tillman, P.G., McKibben, G., Malone, S. and Harsh, D. (1997) Form-Fill-Seal Machine for Mass-Rearing Noctuid Species. In: Remy, K.H., Ed., Office of Agricultural Communications, Division of Agriculture, Forestry, and Veterinary Medicine, Mississippi State University, Technical Bulletin 213, 1-4.

[50] Patana, R. and McAda, W.C. (1973) Tobacco Budworms: Use of Dry Diet Flakes in Rearing. Journal of Economic Entomology, 66, 817-818. https://doi.org/10.1093/jee/66.3.817

[51] Alfazairy, A.A., Sadek, H.A., Guirguis, G.Z. and Karam, H.H. (2012) An Agar-Free Insect Rearing Artificial Diet: A New Approach for the Low Cost Mass Rearing of the Egyptian Cotton Leafworm, Spodoptera littoralis (Boisd.) (Lepidoptera: Noctuidae). Life Science Journal, 9, 4646-4653.

[52] Moore, I. and Navon, A. (1969) Calcium Alginate: A New Approach in the Artificial Culturing of Insects, Applied to Spodoptera littoralis (Boisduval). Experientia, 25, 221-222. https://doi.org/10.1007/BF01899137

[53] Moore, I. and Navon, A. (1973) A New Gelling Technique and Improved Calcium-Alginate Medium for Rearing Spodoptera littoralis. Journal of Economic Entomology, 66, 565-566. https://doi.org/10.1093/jee/66.2.565

[54] Moore, I. and Navon, A. (1974) Gel Texture and Stability of Ascorbic Acid and Its Salts in a Calcium-Alginate Rearing Medium for Spodoptera littoralis (Boisd.). Phytoparasitica, 2, 53-59. https://doi.org/10.1007/BF02980289

[55] Navon, A. (1985) Spodoptera littoralis. In: Singh, P. and Moore, R.F., Eds., Handbook of Insect Rearing, Elsevier Science Publishers, Amsterdam, Vol. 2, 469-475.

[56] Raulston, J.R. and Shaver, T.N. (1970) A Low Agar Casein Wheat Germ Diet for Rearing Tobacco Budworms. Journal of Economic Entomology, 63, 1743-1744. https://doi.org/10.1093/jee/63.6.1743

[57] Leppla, N.C. (1978) Publication of Entomological Techniques. Bulletin of the En- 
tomological Society of America, 24, 21-22. https://doi.org/10.1093/besa/24.1.21

[58] Alverson, J. and Cohen, A.C. (2002) Effect of Antifungal Agents on Biological Fitness of Lygus hesperus Knight (Heteroptera: Miridae). Journal of Economic Entomology, 95, 256-260. https://doi.org/10.1603/0022-0493-95.2.256 